\title{
Comparative analysis of differential gene expression indicates divergence in ontogenetic strategies of leaves in two conifer genera
}

\author{
Cynthia Webster ${ }^{1}$, Laura Figueroa-Corona ${ }^{2}$, Iván Méndez-González ${ }^{2}$, Lluvia Soto-Álvarez ${ }^{3}$, \\ David Neale ${ }^{4}$, Juan P. Jaramillo-Correa ${ }^{5}$, Jill L. Wegrzyn ${ }^{1}$, and Alejandra Vázquez-Lobo ${ }^{3}$ \\ ${ }^{1}$ University of Connecticut \\ ${ }^{2}$ Universidad Nacional Autónoma de México \\ ${ }^{3}$ Universidad Autónoma del Estado de Morelos \\ ${ }^{4} \mathrm{UC}$ Davis \\ ${ }^{5}$ Univ Nacl Autonoma Mexico
}

September 25, 2021

\begin{abstract}
In land plants, heteroblasty broadly refers to a drastic change in morphology during growth through ontogeny. Juniperus flaccida and Pinus cembroides are conifers of independent lineages known to exhibit leaf heteroblasty between the juvenile and adult life stage of development. Juvenile leaves of $P$. cembroides develop spirally on the main stem and appear decurrent, flattened and needle-like; whereas, adult photosynthetic leaves are triangular or semi-circular needle-like, and grow in whorls on secondary or tertiary compact dwarf shoots. By comparison, J. flaccida juvenile leaves are decurrent and needle-like, and adult leaves are compact, short and scale-like. Comparative analyses were performed to evaluate differences in anatomy and gene expression patterns between developmental phases in both species. RNA from twelve samples was sequenced and analyzed with available software. They were assembled de novo from the RNA-Seq reads. Following assembly, 63,741 high quality transcripts were functionally annotated in P. cembroides and 69,448 in J. flaccida. Evaluation of the orthologous groups yielded 4,140 shared gene families among the four references (adult and juvenile from each species). Activities related to cell division and development were more abundant in juveniles than adults in P. cembroides, and more abundant in adults than juveniles in $J$. flaccida. Overall, there were 509 up-regulated and 81 down-regulated genes in the juvenile condition of $P$. cembroides and 18 up-regulated and 20 down-regulated in J. flaccida. Gene interaction network analysis showed evidence of co-expression and co-localization of up-regulated genes involved in cell wall and cuticle formation, development, and phenylpropanoid pathway, in juvenile $P$. cembroides leaves. Whereas in J. flaccida, differential expression and gene interaction patterns were detected in genes involved in photosynthesis and chloroplast biogenesis. Although J. flaccida and P. cembroides both exhibit leaf heteroblastic development, little overlap was detected and unique genes and pathways were highlighted in this study.
\end{abstract}

\section{Hosted file}

Manuscript.docx available at https://authorea.com/users/436859/articles/538896-comparativeanalysis-of-differential-gene-expression-indicates-divergence-in-ontogenetic-strategiesof-leaves-in-two-conifer-genera

\section{Hosted file}

Figure1.tif available at https://authorea.com/users/436859/articles/538896-comparativeanalysis-of-differential-gene-expression-indicates-divergence-in-ontogenetic-strategiesof-leaves-in-two-conifer-genera 


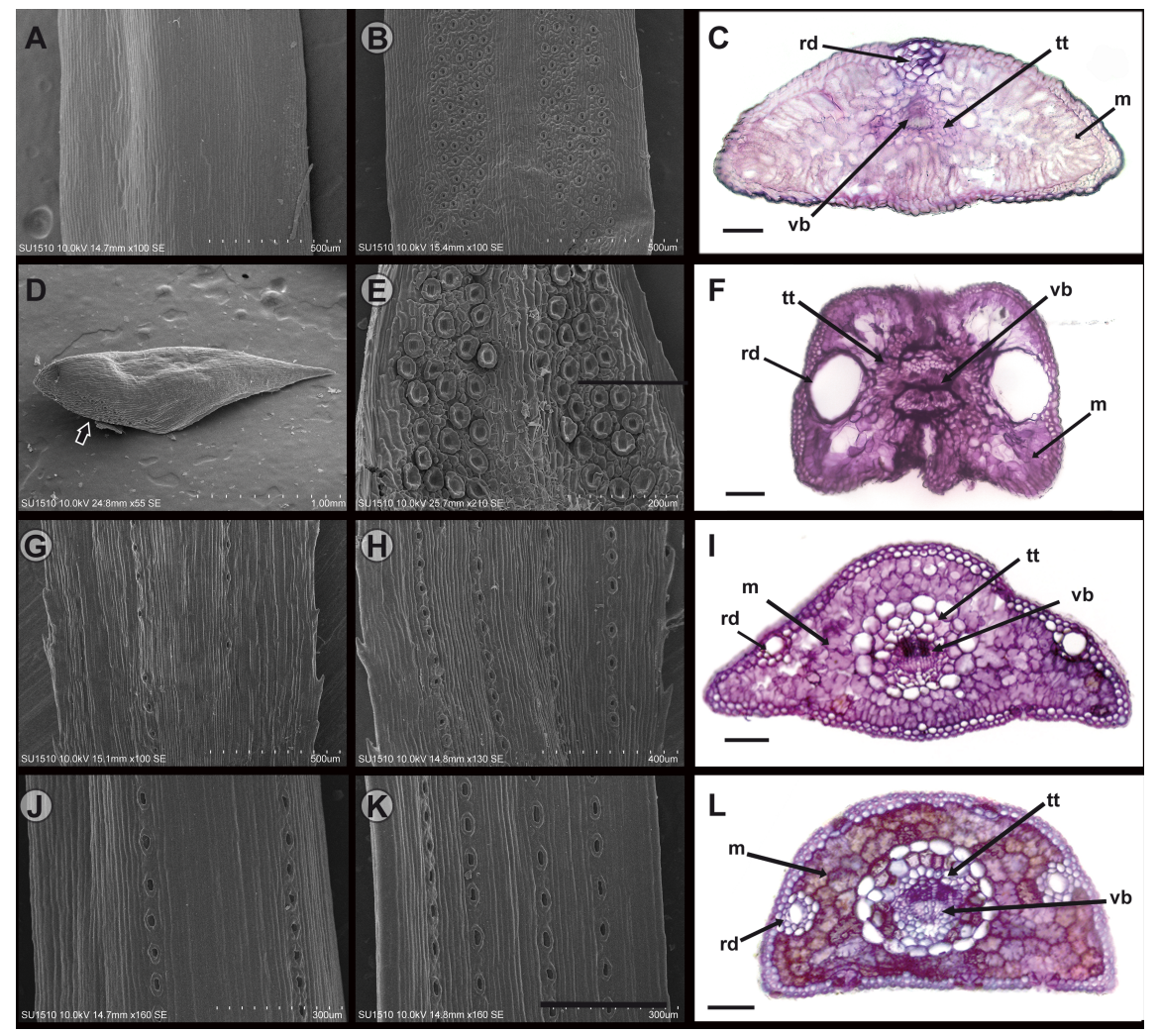


A

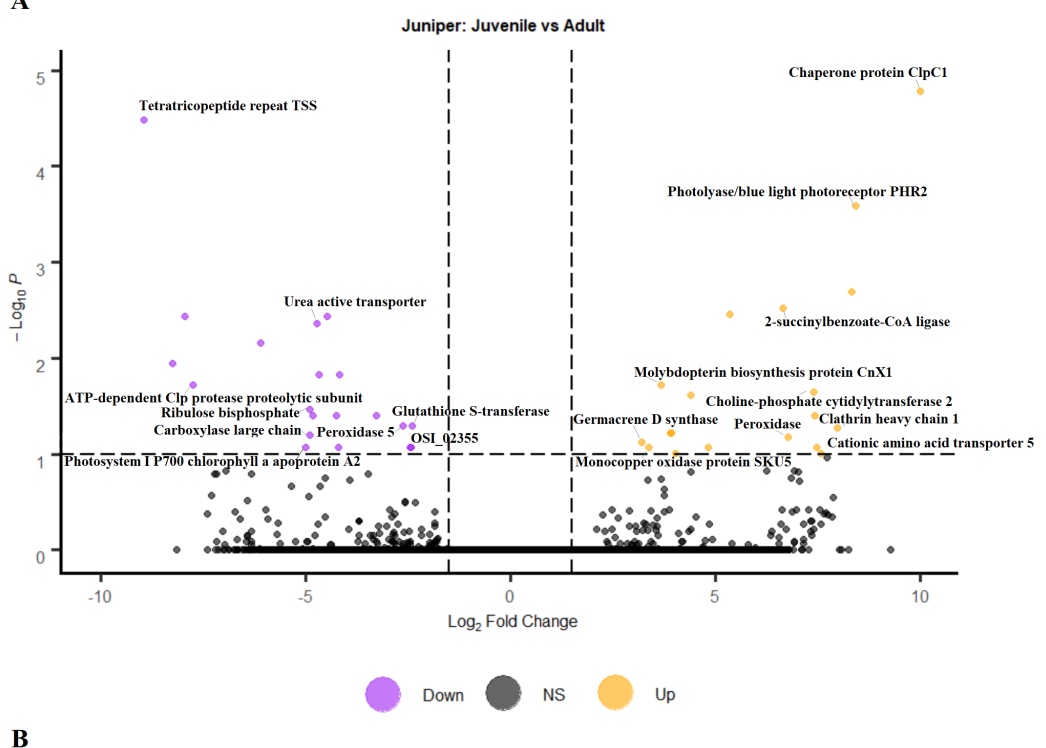

B

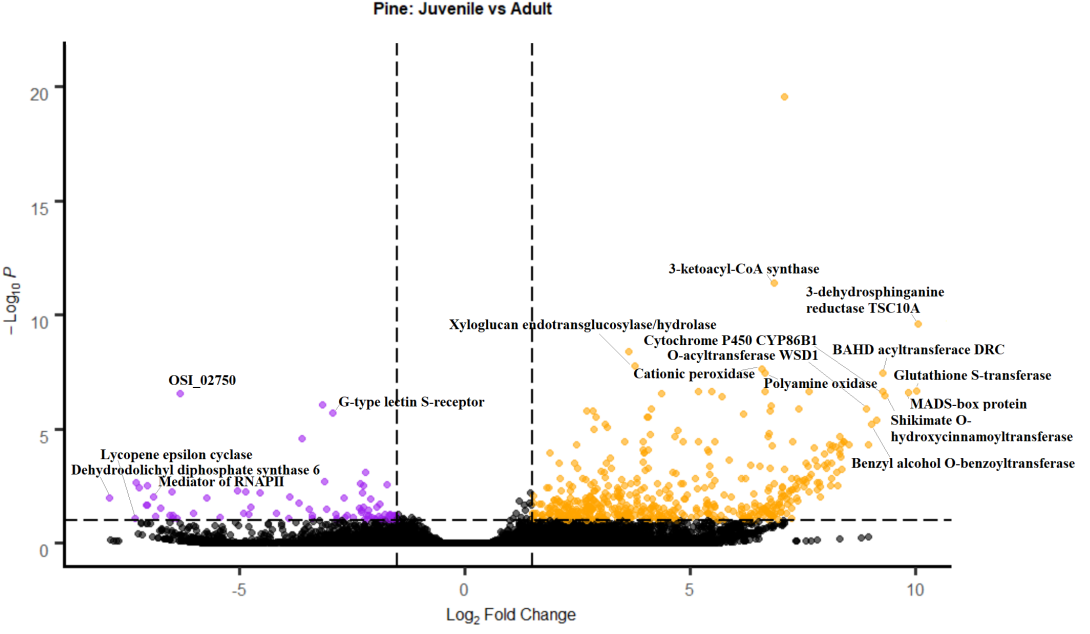




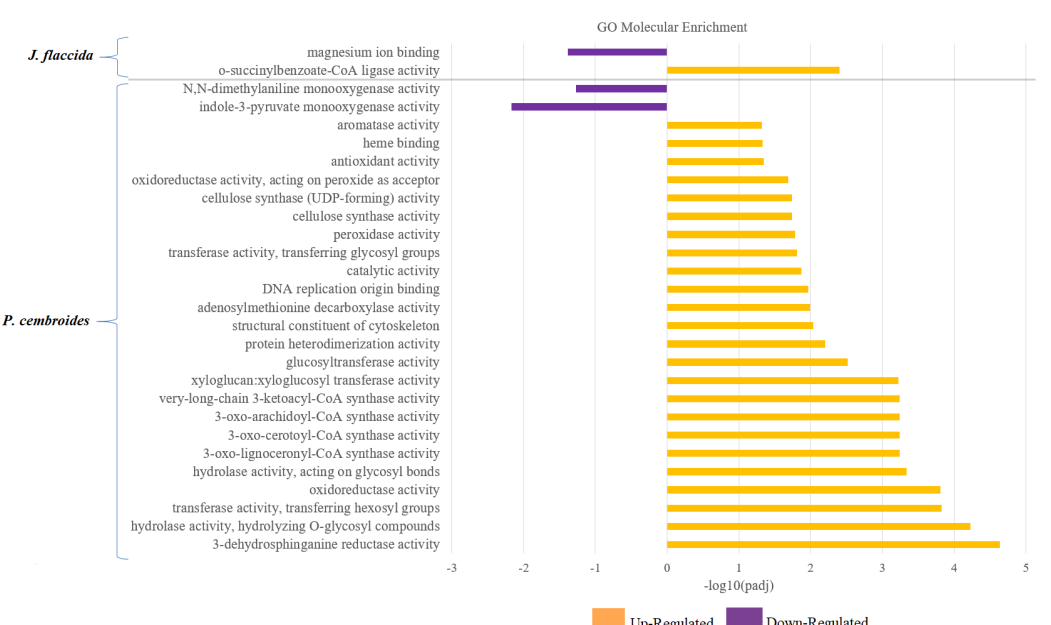

Up-Regulated Down-Regulated

A

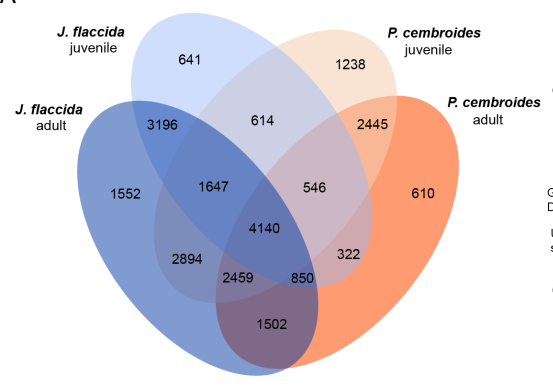

B

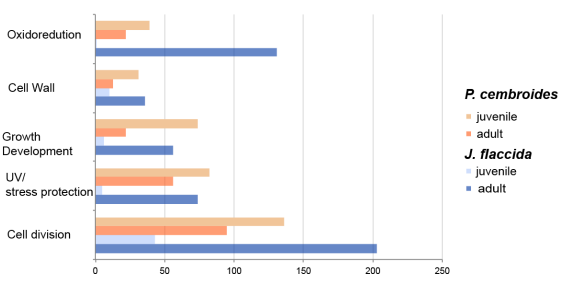

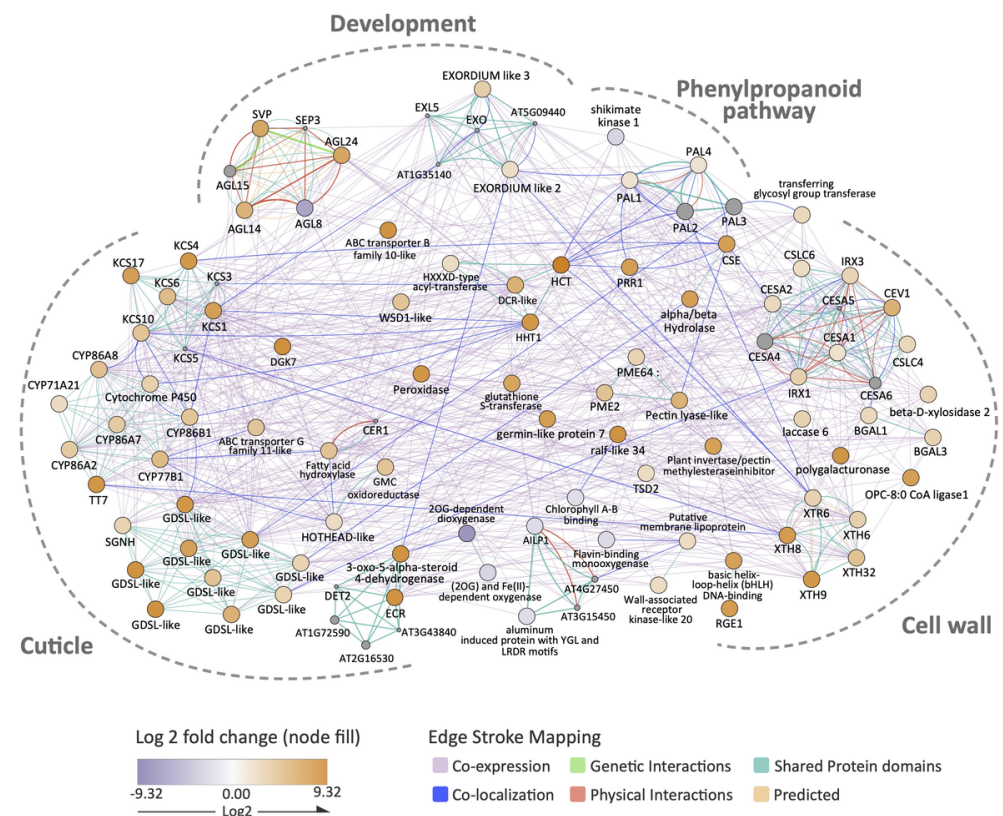




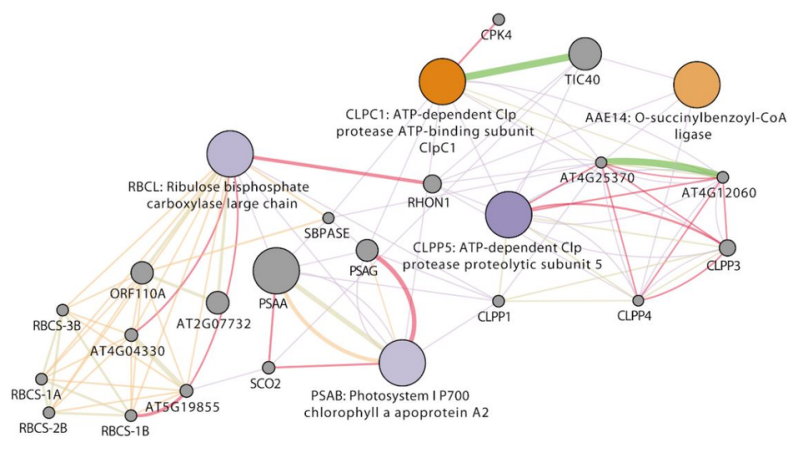

Log 2 fold change (node fill)

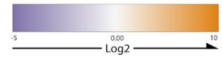

Edge Stroke Mapping

[1] Co-expression

Genetic Interactions

Dhysical Interactions

Predicted

Shared Protein domains 